\title{
Demerit control chart as a decision support tool in quality control of ductile cast-iron casting process
}

\author{
Robert Sika ${ }^{1, *}$, and Michat Rogalewicz ${ }^{2}$ \\ ${ }^{1}$ Poznan University of Technology, Institute of Materials Technology, Piotrowo 3 street, Poland \\ ${ }^{2}$ Poznan University of Technology, Chair of Management and Production Engineering, Piotrowo 3 \\ street, Poland
}

\begin{abstract}
In many industrial areas the product quality can be unequivocally assigned to classes such as: "good", "bad" or "to repair". In case of casting processes, the product is approved to sales considering customer's requirements. Except for common characteristics, such as structure, compactness and mechanical properties, physical state of the product is also important. This state is assessed by checking occurrence of specific kind of defects. They are often conditionally accepted by a customer if they do not have any influence on functionality of the product (e.g. negative adhesive and cohesive phenomena, fatigue strength, thermal shocks). Authors' experience shows that current registering of the most frequently occurring defects and comparing them to customers' requirements can be very useful and help a quality engineer to control the casting process. They suggest using the Demerit Control Chart (DCC), according to authors' own methodology, in aspect of information about the castings accepted conditionally by a customer (DCC-recognition). DCC-recognition can be used to assess this quality by monitoring the value of just one aggregated measure for all kinds of defects instead of using a single attribute control chart for each of them. The test version of this tool considering severity of defects proved to be useful in one of the European foundries.
\end{abstract}

\section{Introduction}

Foundry is one of the most complex manufacturing technologies, comprising of physicochemical processes, including the metallurgical ones. The aim is to obtain a final product (a casting) by shaping it and achieving functional features according to a specifically designed process, considering phenomena of solidification and cooling of a liquid alloy [1-3]. Starting from the $21^{\text {st }}$ century, large organizational and technical changes can be observed in the industry and, what is following, in the foundry branch. The processing technologies, including the foundry, are more and more modern thanks to wider use of innovative industrial machines and improvement of methods of production, control and assessment of processes [4-9]. There is an ongoing trend of supporting this branch of industry

*Corresponding author: robert.sika@put.poznan.pl 
by implementation of innovative projects and processes, such as 3D printing [10] and investing into more and more technologically advanced devices for the casting production [11]. Unfortunately, a still existing problem is high cost of manufactured castings and problems with ensuring their proper quality. In such a context, it is very important to appropriately plan processes of realization of production, organization of these processes and their effective supervision and control.

Manufacturing a final product in a form of a casting consists in realization of many processes, characterized by diversified levels of complexity and influence on the final quality [12]. The multi-staged process and necessity of ensuring quality on each its level, often performed in very changeable conditions, make obtaining a zero defect casting practically impossible. That is why, different from some products manufactured in other machine industry branches (e.g. by machining), it is difficult to unequivocally define and assess quality of a casting [13-14].

A casted product is therefore accepted for sales with consideration of criteria defined by its recipient. Besides basic characteristics, such as compactness of the structure and mechanical properties (often measured on separately cast samples or cast-on samples), state of the product prepared for sending is important. Eventually, the final state of the casting is evaluated for occurrence of specific types of defects (on a surface or inside the casting). What's more, a defect can be often accepted by the customer under certain conditions, if it does not affect usefulness of the product in a negative way (negative adhesive phenomena, fatigue strength, thermal shocks) [13].In foundries, quality control tools are rarely used or not used at all and all activities are taken only after the quality problems already occurred [15]. The authors know situations, when in case of occurrence of a so-called acceptable defect in a casting, quality controllers, due to lack of proper monitoring tools, eventually qualify products as discards (not acceptable for sales).

Considering the technological complexity of casting processes described above and related problems with quality assurance, the authors propose a modification of a tool for aiding quality control of casting processes in a form of a Demerit Control Chart (DCC) [16]. It is used to supervise a number of defects occurring in manufactured series of castings, with consideration of their criticality. This specific control chart was adapted by the authors for use in the foundry branch and it is based on monitoring an aggregated statistics determined for defects, which occurred in a sample of castings taken from each manufactured series. In the further part of the paper, a concept of the DCC will be presented, along with assumptions, methodology of its application in foundry processes and results of its implementation in one of European foundries.

\section{Application of DCC in foundry conditions}

\subsection{Idea of Demerit Control Chart}

The control charts are basic tools of statistical process control and they are used for supervision of a selected characteristics of a process/product through monitoring of changes of a statistic determined out of a sample, taken from this process in set time intervals. Values of a selected statistic (e.g. mean values) are plotted on a sheet of a chart and compared to control limits, representing variability resulting from purely random reasons. Exceeding of control limits or a specific pattern of points appearing in a chart shows that the process is affected by non-random conditions which cause its maladjustment [17].

The control charts are designed for features evaluated in a numerical way (variable charts) or in an alternative way (alternative charts, attributes charts). The first type of chart is usually composed out of two paths: location and dispersion - examples are $\mathrm{x}_{\mathrm{av}}-\mathrm{R}$ or $\mathrm{x}_{\mathrm{av}}-\mathrm{s}$ charts. The 
charts for attributes are plotted with a value of a statistic related to a number of defects or defective units. An advantage of variable charts is possibility of controlling the process and correcting it on-line. The alternative charts do not bring such a possibility. The process evaluation is made post factum - only after it is finished and an appropriately large sample is collected. Despite that these charts require a definitely larger sample than the variable charts and are less informative, they allow current evaluation if defectiveness level of a supervised process does not exceed an acceptable one (this level is determined on the basis of a specifically prepared pilotage trial) [18].

One of types of charts evaluated alternatively are charts related to defects: $c$ - quantity of defects per sample of constant size and $u$ - quantity of defects per unit. Their important assumption, which is sometimes a limitation, is treatment of each defect detected in a collected sample with equal importance. If, for a given process or phenomenon, it is advisable to consider certain defects as more important than the other ones, which is a case in foundry processes, it is worthy to use a Demerit Control Chart (DCC).

The DCC sheet is plotted with a statistic aggregating all the defects in a collected sample and taking their different importance into consideration. In literature [16, 19], it is recommended to apply 4 different classes and weights for the defects: class $\mathrm{A}$ - very serious defects - weight 100 , class B - serious defects - weight 50, class C - moderately serious defects - weight 10 , class D - not serious defects - weight 1.

Appropriate selection of these weights is very meaningful for the DCC. It is important for it not to be too sensitive to defects of low seriousness, with still being sensitive to the most relevant ones. Usually, values of weights are determined for a given problem. Assumptions and conditions regarding the use of DCC in casting processes are presented in the next subchapter.

\subsection{Assumptions for use of DCC in casting processes}

Cooperation with experienced quality controllers from European cast iron foundries allowed to conclude, that concept of the DCC can be successfully translated into industrial conditions in a foundry. However, it is important to modify approach for use of this chart, to take specific conditions of casting production into account. The most important assumptions are shortly described in the next paragraphs.

First of all, assessment of defects of castings is still performed by visual testing in most cases (VT method). It means that a casting is evaluated for a given defect without use of additional measurement tools (more accurate). Additionally, considering classification of criticality, a division into 4 classes suggested in the literature may be not justified in case of casted products. At most 3 cases can be distinguished here ( $\mathrm{C} 1, \mathrm{C} 2$ and $\mathrm{C} 3$ ):

- $\mathrm{C} 1$ - a casting has a defect of such a size and/or dispersion that is making it impossible to sell it.

- $\mathrm{C} 2$ - a casting has a defect of a size and/or dispersion, which allows selling it under certain, strictly defined conditions (it is necessary to perform an additional study by another controller, preferably from outside the company) - however, such cases occur relatively rarely.

- C3 - a casting has a defect of a size and/or dispersion which usually allows selling it (does not cause any mechanical failures during standard operation of a product).

The second important issue of the proposed approach is classification of criticality of defects and assigning them with appropriate ranges. The authors decided not to make constant assumptions of certain types of defects being more or less critical. A given type of defect is assigned to a specific class of criticality each time, because depending on its size and/or dispersion it can take different weights. The most frequently (approx. 70-80\% per each series) it is a $\mathrm{C} 1$ class. In other cases, the castings may be classified by a specific defect as $\mathrm{C} 2$ or $\mathrm{C} 3$. 
The authors propose to name this approach the "DCC-recognition" (this notion will be used in the further part of the paper interchangeably with the DCC acronym), as large emphasis must be put on proper "recognition" of a class of a defect, due to criticality of its size and/or dispersion. As already mentioned, this "recognition" should be performed for each defect which occurred separately, without assigning constant weights for a specific type of defect.

The third important issue is reliable mapping of an analyzed process and definition of types of defects which may occur during this process. The authors propose that in scope of preparation of design of the DCC-recognition, selection of a specific type of casting for supervision (e.g. the most frequently produced) should be made in the first place and then a study should be made to answer what types of defects are the most frequently repeated for the casted series of this product. It is worth to select at most several defects, which are repeatable. A problem of mapping of the analyzed process is described in greater detail in the chapter 3 .

It is noteworthy, that authors of this paper do not define precise nomenclature of defects assigned to cast iron castings. There is a considerable number of existing divisions, standards and atlases of defects, as well as branch standards. The methodology presented in the further part of the paper is suitable for practically any classification of defects, while this work shows its use in casting of cast iron.

The last important factor related to implementation of the DCC in foundry is selection of size of a pilotage trial. An advantage of this chart is a fact, that size of each subsequent sample collected from the process can be variable, what is important in case of different sizes of casted series. The authors propose, for the needs of the DCC-recognition, to collect and accurately evaluate randomly taken $10 \%$ of castings of each series. In practice, when quantity of a series is high, not all castings are investigated with $100 \%$ accuracy. It seems that $10 \%$ of castings investigated accurately will be a good representative of the whole casted series. A lot of defective castings are discovered after machining.

\subsection{Methodology of design of DCC-recognition}

Considering the guidelines presented in the previous chapter, methodology of implementation of the DCC into foundry processes on example of castings out of ductile cast iron is presented. This methodology is universal and can be adjusted for use in other processes of similar character, while its particular steps consider assumptions presented in the chapter 2.2. More details about particular steps of the methodology are presented in the further part of the paper.

- STEP 1: Mapping of analyzed process and defining defects, which may occur - on the basis of history of problems with a given process or with similar processes (for new processes), it should be determined which defects may occur in the process.

- STEP 2: Determination of classes of criticality of defects and assigning them with weights - due to specificity of the casting process, 3 classes were assumed: C1 (weight 10), C2 (weight 5), C3 (weight 1).

- STEP 3: Collecting a pilotage trial from a process as far as possible in the most beneficial conditions - the pilotage trial will be a ,master pattern", that is referred to results of the current process control.

- STEP 4: Determination of an average number of Demerit per unit and standard deviation related to it:

An average number of Demerit per unit is expressed by the formula (1):

$$
\overline{\mathrm{u}}=\mathrm{w}_{\mathrm{c1}} \overline{\mathrm{u}}_{\mathrm{c} 1}+\mathrm{w}_{\mathrm{c} 2} \overline{\mathrm{u}}_{\mathrm{c} 2}+\mathrm{w}_{\mathrm{c} 3} \overline{\mathrm{u}}_{\mathrm{c} 3}
$$


For example, for the $\mathrm{C} 1$ class the following formulas should be used (2):

where:

$$
\begin{gathered}
u_{j_{c 1}}=\frac{\sum_{i=1}^{n_{j}} x_{i_{c 1}}}{n_{j}} \\
\overline{\mathrm{u}}_{\mathrm{cl}}=\frac{\sum_{\mathrm{j}=1}^{\mathrm{k}} \mathrm{u}_{\mathrm{j}_{\mathrm{c} 1}}}{\mathrm{k}}
\end{gathered}
$$

$\mathrm{u}_{\mathrm{j}}$ - number of defects per casting in sample $j$

$j$ - number of a specimen in a pilotage trial $(j=1,2, \ldots, \mathrm{k})$

$k$ - number of specimens in the pilotage trial

$w_{c}$ - weight of defect belonging to the $c$ class (according to the previous assumptions for the needs of foundry, the following values were assumed: $w_{c l}=10, w_{c 2}=5, w_{c 3}=1$ )

$i$ - number of a casting in a sample $\left(i=1,2, \ldots, n_{j}\right)$

$x i$ - number of defects in a casting

$n_{j}$ - quantity of $j$ sample of castings

Standard deviation related to the average Demerit number per unit is calculated using the following formula (3):

$$
\hat{\sigma}_{u}=\sqrt{\frac{\left(w_{c 1}\right)^{2} \bar{u}_{c 1}+\left(w_{c 2}\right)^{2} \bar{u}_{c 2}+\left(w_{c 3}\right)^{2} \bar{u}_{c 3}}{n}}
$$

- STEP 5: Determination of control limits in a DCC and plotting points from the pilotage trial. The control limits are determined using the following formulas (4):

$$
C L=\bar{u} \quad L C L=\bar{u}-3 \hat{\sigma}_{u} \quad U C L=\bar{u}+3 \hat{\sigma}_{u}
$$

- STEP 6: If points in a chart indicate existence of maladjustment while collecting the pilotage trial - identification and elimination of its cause and re-calculating the control limits.

- STEP 7: Supervision of a process, consisting in collecting a sample from each series of castings, determining the D number per unit and plotting this value in a chart, as well as observing potential symptoms in a chart. The control chart is plotted with a statistic using the following formula (5):

$$
\mathrm{u}_{\mathrm{j}}=\frac{\mathrm{w}_{\mathrm{cl}} \mathrm{u}_{\mathrm{c} 1}+\mathrm{w}_{\mathrm{c} 2} \mathrm{u}_{\mathrm{c} 2}+\mathrm{w}_{\mathrm{c} 3} \mathrm{u}_{\mathrm{c} 3}}{\mathrm{n}_{\mathrm{j}}}
$$

\section{Application of DCC in a process of ductile cast iron casting}

The studies were realized in an European foundry manufacturing cast iron castings for the machine industry. The net weight of a single product (without the gating system and the risers) is $3,45 \mathrm{~kg}$ and it is manufactured on a modern automated box-less line with a vertical mold division. Daily, the company (in a 3-shift system) produces up to several dozen types of castings, with one series between several hundred to even 1000 pieces of castings (depending on the weight of casting). An example shown below refers to a specific melt and 
assortment produced in series. In scope of the pilotage trial, aggregated part of occurring of 3 the most commonly present defects for this assortment is presented. According to nomenclature by the Polish Standard PN-85 H-83105 they are the W101 (mechanical damages), W202 (blows) and W222 (sand holes) [20]. Table 1 presents data related to preparation of the pilotage trial and implementation of the DCC-recognition.

Table 1. Data related to pilotage trial preparation and DCC-recognition chart application.

\begin{tabular}{|c|c|c|}
\hline Differentiating feature & $\begin{array}{c}\text { Data according to } \\
\text { pilotage trial }\end{array}$ & $\begin{array}{c}\text { Data according to } \\
\text { DCC-recognition }\end{array}$ \\
\hline Period of testing: & $\begin{array}{c}\text { January }- \text { June } \\
2016\end{array}$ & $\begin{array}{c}\text { July }- \text { August } \\
2016\end{array}$ \\
\hline Number of series: & $20 \mathrm{pcs}$. & $7 \mathrm{pcs}$. \\
\hline $\begin{array}{c}\text { Number of castings in series } \\
\text { (min / max / average): }\end{array}$ & $\begin{array}{c}260 / 1045 / 688 \\
\mathrm{pcs} .\end{array}$ & $\begin{array}{c}285 / 995 / 584 \\
\mathrm{pcs} .\end{array}$ \\
\hline Weight of the casting net/gross: & $3,45 / 4,8 \mathrm{~kg}$ & $3,45 / 4,8 \mathrm{~kg}$ \\
\hline Number of defective castings (C1/C2 / C3): & $90 / 16^{*} / 30^{* *}$ & $28 / 5^{*} / 9^{* *}$ \\
\hline
\end{tabular}

*) cases must be approved for sale with participation at least 2 controllers

**) cases may be approved for sale with participation at least 2 controllers (depends on the quality control regime)

For the needs of testing the presented methodology, a computer tool was designed for improving of casting defects evaluation in an electronic version of the DCC-recognition -see Figure 1.

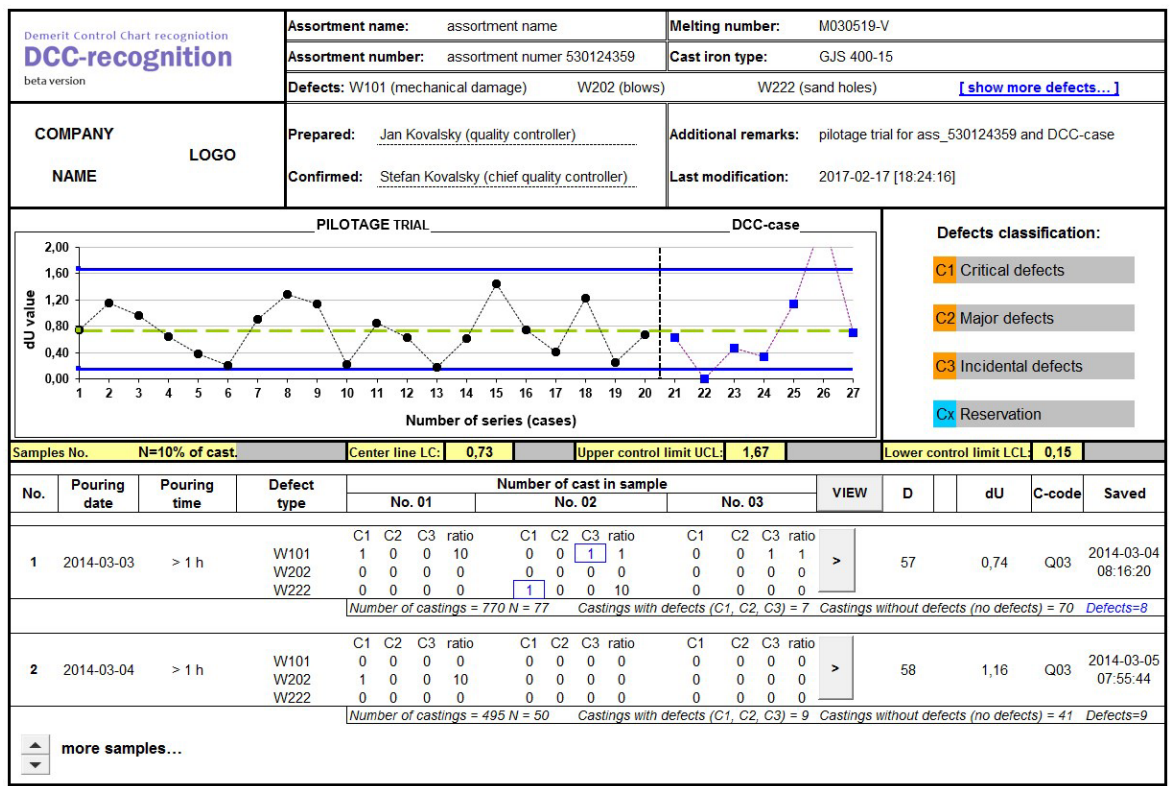

Fig. 1. DCC-recognition - an example of electronical control chart for assortment 530124359

The chart in its electronical shape allows displaying basic information about the currently casted series (assortment name, assortment number, melting number, cast type iron and information about defects) in a form readable for an employee. Moreover, it contains additional information, such as: a person responsible for the chart, data of modification, supplementary information. Central part of the chart is occupied by a diagram with a possibility of displaying last 30 values of samples. Below the diagram, there is a panel, 
which allows recording cases for a randomly selected sample of each series (number of a casting in a sample, type of defect, class of defect, causes and preventive reactions) - see Fig. 2.

As it can be read from a sheet of the DCC (Fig. 1), first 20 samples were used to estimate basic characteristics of this chart (central line, upper and lower control limits). Formulas presented in chapter 2.3 were used. As presented, during the realization of the process for samples belonging to the pilotage trial, the process was stable - no maladjustment symptoms occurred. It means, that the control limits can be used for on-line supervision of the casting process. Another 7 measurements (21-27) are samples collected during realization of the process. For the series no. 6 (point 26), the chart indicated slight exceeding of the upper control limit. It is a valuable information for the quality controllers. It means that the number, type or criticality of occurring defects is higher than during collection of the pilotage trial and if no intervention is made in the process, the next series can present similar problems in production quality.

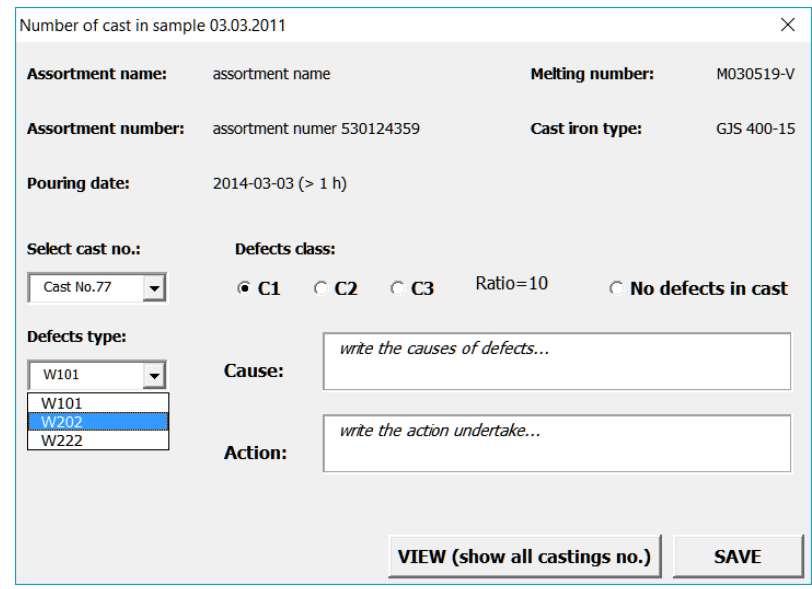

Fig. 2. Exemplary screen of the DCC-recognition - registering defect class for a sample.

\section{Summary}

The paper presents an example of implementation of a control chart for quality inspection and control of defects of casting (features evaluated alternatively) in the foundry industry. Although this type of chart does not allow current correction of the process, it is a valuable source of information for the quality assurance division, on problem of aggregated value of defects present for particular series of a specific assortment, with division into classes of criticality.

It turns out, that the proposed DCC-recognition allows, among other things, to systematize and order classes of defects occurrence by criticality. The authors think that the proposed methodology will be an encouragement for the foundries that unequivocally evaluate defects of castings and do not allow selling of products with acceptable defects. It is a matter which has been discussed for a long time between clients and suppliers (foundries). All conditions of selling of defective castings should be, obviously, settled with client beforehand (such as location of a defect, its size and dispersion).

A methodology was proposed and a tool based on it, in a form of an electronical chart (DCC-recognition), which is a new approach to monitoring of defects of casted products. Employees of the Quality Assurance division have a possibility of on-line supervision of 
aggregated criticality of occurrence of the most commonly observed defects in castings series, which makes it possible to take more accurate actions (differentiation between the class C1 - casting not sold - from the classes C2 and C3). As it turns out, average of $25 \%$ of cases of investigated castings can be directed for further selling.

\section{References}

1. 49th Cens. of Word Cast. Product., Modest Grow. in Worldw. Cast. Mark., http://www.globalcastingmagazine.com/ (2016)

2. D.R. Cooper, World Found. Cong., 71, World Foundry Congress, http://www.thewfo.com/contentfiles/pdfs/27.pdf (2014)

3. Moulding - traditition and modernity (in Polish), http://www.odlewnictwo.agh.edu.pl/ (2016)

4. A. Kujawinska, K. Vogt, F. Wachowiak, edited by: P. Golinska, A. Kawa, Technol. Manag. For Subst. Prod. and logist., Book Series: EcoProduction, 193 (2015)

5. M. Diering, K. Dyczkowski, A. Hamrol, 10th Int. Conf. on Soft Comp. Mod. in Ind. and Envir. Appl., Spring. Intern. Publ. Switz., 368, 415 (2015)

6. M. Diering, K. Dyczkowski, IEEE Int. Conf. on Ind. Eng. and Eng. Manag., 2016, 228 (2016)

7. G. Vieira, L. Reis, M.L.R. Varela, J. Machado, J. Trojanowska, Rom. Rev. Prec. Mech. Opt. and Mechatr., 50, 119 (2016)

8. J. Trojanowska, K. Żywicki, E. Pająk, Inf. Technol. in Envir. Eng., 695 (2011)

9. P. Zawadzki, F. Górski, A. Hamrol, M. Kowalski, R. Paszkiewicz, Trans. of FAMENA, 35, 69 (2011)

10. W. Kuczko, F. Górski, R. Wichniarek, P. Zawadzki, P. Buń, Adv. in Sc. and Technol. Res. J., 9(26), 20 (2015)

11. R. Sika, Z. Ignaszak, Arch. of Found. Eng., 5, 145 (2016)

12. I.G. Vidayev, N. Martyushev, A. Ivashutenko, A.M. Bogdan, Adv. Mat. Res., 880, 141 (2014)

13. Z. Ignaszak, J. Ciesiółka, Weld. Over., Conditions and prospects for non-destructive testing of castings before their exploitation - chapter II (in Polish), 83(13), 36 (2011)

14. Z. Ignaszak, J. Hajkowski, P. Popielarski, Def. and Diff. Forum, 336, 135 (2013)

15. M. Salem, S. Maik, J. Gottschling, D. Hartman, http://www.researchgate.net/ (2014)

16. L.H. Chen, J. Intell. Manuf., 16(3), 349 (2005)

17. M. H. Omar, J. of Educ. Measur., 47, 18, (2010)

18. T.R.Vijayaram, S. Sulaiman, A.M.S. Hamouda, M.H.M Ahmad, J. of Mat. Proc. Technol., 178, 39 (2006)

19. M. L. Crossley, ASQ Quality Press, The Desk Reference of Statistical Quality Methods. Demerit/Unit Control Chart, 127 (2008)

20. PN-85 H-83105, Castings. Classification and defects terminology (in Polish),(1985) 